\title{
Biodiversity: the chasm between what we know and we need to know.
}

\author{
WILLIAM E. MAGNUSSON \\ Coordenação da Biodiversidade (CBIO), Instituto Nacional de Pesquisas da Amazonia/ \\ INPA, Av. André Araújo, 2936, Petrópolis, 69067-375 Manaus, AM, Brazil \\ Manuscript received on January 23, 2019; accepted for publication on April 15, 2019
}

\begin{abstract}
How to cite: MAGNUSSON WE. 2019. Biodiversity: the chasm between what we know and we need to know. An Acad Bras Cienc 91: e20190079. DOI 10.1590/0001-3765201920190079.

Abstract: In this review I focus on what we need to know to make decisions relevant to land-use planning. I discuss four questions: What information about the distribution of biodiversity is available to decision makers? What sort of information is required at a local scale? Can we use species-distribution modeling to compensate for the lack of empirical information at larger scales? Can we use surrogates based on remote sensing for all our decisions? To be effective, biodiversity information needs to be based on standardized sampling with data made available during the initial planning phases of infrastructure projects, which are now based only on engineering or social considerations and occur several decades before construction starts. The RAPELD method is now being used in many environmental-impact studies to generate standardized data, but there is presently no mechanism to include biodiversity information in the initial phases of decision making, and this has unfavorable consequences for economic development and the environment.
\end{abstract}

Key words: research, finance, geographical bias, management, systematic conservation planning.

The title of this paper is obviously so encompassing that it would be impossible to treat the subject in a single publication. Therefore, I will concentrate on what we need to know to make decisions relevant to land-use planning. Almost all decisions about management of biodiversity require spatiallyexplicit information, and that is lacking for most species and areas throughout Brazil.

I will present case studies from Brazil, but most of the considerations apply to other South American countries. I will discuss four questions: What information about the distribution of biodiversity is available to decision makers? What sort of information is required at a local scale? Can we use

E-mail: bill@inpa.gov.br / wemagnusson@gmail.com ORCID: http://orcid.org/0000-0003-1988-3950 species-distribution modeling to compensate for the lack of empirical information at larger scales? Can we use surrogates based on remote sensing for all our decisions?

Before considering these questions, it is important to emphasize that the type of data required for land-use decisions is different from most data being collected by biologists (Mazor et al. 2018). Land-use decisions require information on biotic complementarity: that is, which elements of biodiversity occurring in one area do not occur in another. This is the concept behind all systematic conservation planning (Margules and Pressey 2000), which basically follows economic theory. A resource that is widely available will have less value, and hence less weight in decision-making, than a resource that has a restricted distribution. 
Information on biodiversity is strongly concentrated near major human population centers. This information is frequently historical as little biodiversity remains there today, and recovering it would be prohibitively expensive. This produces what Magnusson et al. (2016) described as a veil line, with most of the areas with the highest biodiversity being under sampled. Worse still, they show that most of the investments in biodiversity research are being concentrated in areas where we know the most, because those are the areas in which most professional biologists reside. Although it could be argued that easy access promotes longterm studies, the ratio of long-term to one-off studies is no greater in the regions close to large population centers.

Systematic conservation planning requires systematically-collected data, but many researchers claim that citizen science or historical collections can replace field sampling, which is difficult and not fashionable in a highly technological society. Unfortunately, museum data has many limitations (Gaiji et al. 2013). Also, when false absences due to under sampling are common, which is the case for most biological groups in most parts of South America, the standard techniques for conservation planning based on complementarity give priority to areas with greater sampling intensity (Magnusson et al. 2013). This results in more resources being invested in the areas that have been most studied. That is fortunate for biologists who live in major population centers and do not have time to travel long distances, but may be insidious for biodiversity conservation in areas where more people are dependent on biodiversity for economic sustainability (Magnusson et al. 2016).

Evaluations of environmental impacts in Brazil have traditionally been couched in terms of ecological statistics, such as species richness or compound indices of diversity. However, these have very little use in systematic conservation planning (Magnusson et al. 2013), and the RAPELD method for spatial standardization is now required in many environmental-impact studies. Graphs that show the spatial distribution of biodiversity, such as Figure 2 in the paper by Carneiro et al. (2016), are necessary to identify species at risk locally due to infrastructure projects. However they are of limited use for planning once the location of the intervention has been determined. In many cases, complementarity of species assemblages may not be adequate and there also needs to be analysis of complementarity of species interactions, such as facilitation, competition and predation. To be effective, such information needs to be available during the initial planning phases, which are currently mainly based on engineering or social considerations, and usually occur several decades before the evaluation of impacts on biodiversity is undertaken.

Large infrastructure projects almost always result in the complete elimination of the original biological assemblages in at least part of the affected area. Therefore, asking whether there will be an effect is trivial. The question is whether the project will result in the loss of a large proportion of elements of the country's biodiversity, such as species or unique assemblages. For that, it is necessary to have information on biodiversity outside the impact area, which is generally not required in impact assessments. If all studies of environmental impacts included some standardized sampling, and the data were made freely available, the huge data deficit beyond the veil line could be greatly reduced (Costa and Magnusson 2010).

It is frequently claimed that species-distribution models can be used to substitute systematic sampling. This may be true for some biological groups that have been extensively studied, such as birds and large mammals. However, most of the species identified as at risk in environmentalimpact assessments are likely to have few data available from museum collections, or represent undescribed species whose distributions outside the impact area are entirely unknown (Carneiro et al. 2016). Therefore, species-distribution modeling should not be considered an end in itself, but as a tool to show where standardized sampling should be undertaken for validation and calibration. 
The coarsest form of species-distribution modeling involves the use of large-scale landscape categories as surrogates for species distributions. These are often phyto-physiognomies, ecoregions or, in the case of Amazonia, endemism areas. These supposed boundaries of species distributions are often based on flimsy evidence, and should be validated by systematic sampling across their borders (Magnusson 2004). Centers of endemism (Cracraft 1985, Ribas et al. 2011) are often used for conservation planning in the Amazon (Silva et al. 2005). While they may have validity for a few taxonomic groups, they are largely irrelevant for more than $99 \%$ of animal species (Santorelli et al. 2018) and probably a much larger percentage of plant species.

Environmental-impact studies have the potential to generate a huge amount of data that can be used in academic studies (e.g. Fraga et al. 2017, Oliveira et al. 2018). Perhaps more importantly, standardized sampling in academic studies could be used to complement impact studies and allow systematic conservation planning across the entire continent. Cuts to the Brazilian science budget have stopped or eliminated important biodiversity monitoring initiatives (Fernandes et al. 2017, Magnusson et al. 2018). This short-term planning by government will have large costs for the environment and the Brazilian economy in the coming years.

\section{ACKNOWLEDGMENTS}

The ideas behind this article were developed while I held a productivity grant from Conselho Nacional de Desenvolvimento Científico e Tecnológico (CNPq, Pq 301873/2016-0) and the practical applications were based on the experience of the Brazilian Program for Biodiversity Research (PPBio) and the National Institute for Amazonian Biodiversity (INCT-CENBAM).

\section{REFERENCES}

CARNEIRO LRA, LIMA AP, MACHADO RB AND MAGNUSSON WE. 2016. Limitations to the use of species-distribution models for environmental-impact assessments in the Amazon. Plos One 11: e0146543. DOI.10.1371/journal.pone.0146543.

COSTA FRC AND MAGNUSSON WE. 2010. The need for large-scale, integrated studies of biodiversity - the experience of the Program for Biodiversity Research in Brazilian Amazonia. Nat \& Cons 8: 3-12.

CRACRAFT J. 1985. Historical biogeography and patterns of differentiation within the South American avifauna: areas of endemism. Ornith Monogr 36: 49-84.

FERNANDES GW ET AL. 2017. Dismantling Brazil's science threatens global biodiversity heritage. Perspectives Ecol Conserv 15: 239-243.

FRAGA R, LIMA AP, MAGNUSSON WE, FERRÃO M AND STOW AJ. 2017. Contrasting patterns of gene flow for Amazonian snakes that actively forage and those that wait in ambush. J Hered 108: 39-243.

GAIJI S, CHAVAN V, ARIÑO AR, OTEGUI J, HOBERN D, SOOD R AND ROBLES E. 2013. Content assessment of the primary biodiversity data published through GBIF Nework: Status, challenges and potentials. Biodiv Inform 8: 94-172.

MAGNUSSON WE. 2004. Ecoregion as a pragmatic tool. Cons Biol 18: 4-10.

MAGNUSSON WE ET AL. 2013. Biodiversity and Integrated Environmental Monitoring. Manaus: Attema, 351 p.

MAGNUSSON WEETAL. 2016. Alinha de véu: a biodiversidade brasileira desconhecida. Parc Estrat 21: 45-60.

MAGNUSSON WE ET AL. 2018. Effects of Brazil's political crisis on the science needed for biodiversity conservation. Front Ecol Evol 8: 163. DOI: 10.3389/fevo.2018.00163.

MARGULES CR AND PRESSEY RL. 2000. Systematic Conservation Planning. Nature 405: 243-253.

MAZOR T, DOROPOULOS C, SCHWARZMUELLER F, GLADISH DW, KUMARAN N, MERKEL K, DI MARCO M AND GAGIC V. 2018. Global mismatch of policy and research on drivers of biodiversity loss. Nature Ecol Evol 2: 1071-1074.

OLIVEIRA WL, MEDEIROS MB, SIMON MF, HAY J AND TER STEEGE H. 2018. The role of recruitment and dispersal limitation in tree community assembly in Amazonian forests. Plant Ecol Div 11: 1-12.

RIBAS C, ALEIXO A, NOGUEIRA ACR, MIYAKI CY AND CRACRAFT J. 2011. A palaeobiogeographic model for biotic diversification within Amazonia over the past three million years. Proc Roy Soc B. 279: 681-689.

SANTORELLI S, MAGNUSSON WE AND DEUS CP. 2018. Most species are not limited by an Amazonian river postulated to be a border between endemism areas. Sci Rep 8: 2294. DOI: 10.1038/s41598-018-20596-7.

SILVA JMC, RYLANDS AB AND FONSECA GAB. 2005. The fate of the Amazonian areas of endemism. Cons Biol 19: 689-694. 